\title{
SUSTENTABILIDADE EMPRESARIAL: CONSIDERAÇÕES SOBRE DIFERENTES SISTEMAS DE MENSURAÇÃO DO DESENVOLVIMENTO SUSTENTÁVEL
}

\author{
A. M. IMPERADOR ${ }^{1}$, M. V. H. SILVA ${ }^{2}$ \\ Universidade Federal de Alfenas \\ adriana.imperador@unifal-mg.edu.br \\ Submetido 02/05/2017 - Aceito 08/03/2018 \\ DOI: $10.15628 /$ holos.2018.5916
}

\section{RESUMO}

A mensuração da sustentabilidade empresarial é um tema complexo e fundamental para a operacionalização do desenvolvimento sustentável na rotina diária das organizações. Por isso, inúmeros sistemas foram desenvolvidos após o alerta apresentado pela Agenda 21 Global quanto à sua importância. Apesar da existência desses vários sistemas, algumas lacunas ainda impedem a inclusão da sustentabilidade na agenda operacional das organizações, dentre elas a falta de congruência em relação ao seu conteúdo. Por isso, o objetivo deste trabalho foi desenvolver uma análise comparativa da dimensão ambiental entre diferentes sistemas de mensuração do desenvolvimento sustentável (SMDS) corporativo. Para tanto, comparouse cinco dos principais sistemas: Global Reporting Initiative (GRI), Índice Dow Jones de Sustentabilidade (DJSI), Indicadores Ethos de Responsabilidade Social Empresarial, Índice de Sustentabilidade Empresarial BM\&F-Bovespa (ISE) e a Norma ISO 26.000. O trabalho compara diferentes níveis de profundidade na gestão da sustentabilidade empresarial e apresenta temas prioritários como Água, Energia, Resíduos, GEE e Biodiversidade. O GRI apresenta critérios mais profundos e detalhados na dimensão ambiental, sendo o único a objetivamente avaliar metas quantitativas na performance ambiental.

\section{CORPORATE SUSTAINABILITY: A COMPARATIVE ANALYSIS BETWEEN DIFFERENT SUSTAINABLE DEVELOPMENT MEASUREMENT SYSTEMS}

\begin{abstract}
The measurement of corporate sustainability is a complex and critical issue for the operationalization of sustainable development into the daily routine of organizations. Therefore, many systems were developed after the warning presented by the Global "Agenda 21". Despite the existence of these various systems, some gaps still hinder the inclusion of sustainability into the operational agenda of organizations. Among them the lack of congruence in relation to its content submitted by different systems. Therefore, the aim of this study was to develop a comparative analysis in the
\end{abstract}

environmental dimension between different corporate sustainable development measurement systems. For this, was compared five major systems of corporate sustainability measurement: Global Reporting Initiative (GRI), the Dow Jones Sustainability Index (DJSI), Ethos Indicators of Corporate Social Responsibility, Corporate Sustainability Index from BM\&F-Bovespa (ISE) and ISO 26.000. This study shows different depths in the management of corporate sustainability and presents priority themes such as Water, Energy, Waste, GHG and Biodiversity.

KEYWORDS: Corporate Sustainability, Sustainability Indicators, Sustainable Development Measurement System 


\section{INTRODUÇÃO}

O capitalismo, de forma geral, é um modelo econômico que se baseia no princípio da acumulação do capital. Para tanto, os sistemas de produção e o mercado, em suas diversas modalidades, se mantêm em função dos lucros, e o consumo em massa garante a dinâmica deste sistema de acumulação. Já a sustentabilidade, assim como o desenvolvimento sustentável, pode ser entendida como um conceito político, que se baseia na capacidade de manter os três pilares fundamentais de forma igualitária e sistêmica: econômico, social e ambiental, visando à continuidade da vida (Simons, Slob, Holswilder, \& Tukker, 2001). A Figura 1 mostra a representação das dimensões da sustentabilidade, reforçando a necessidade de definir apropriadamente limites de um sistema ecológico quando mensurando a performance em sustentabilidade (Ostrom, 2009).

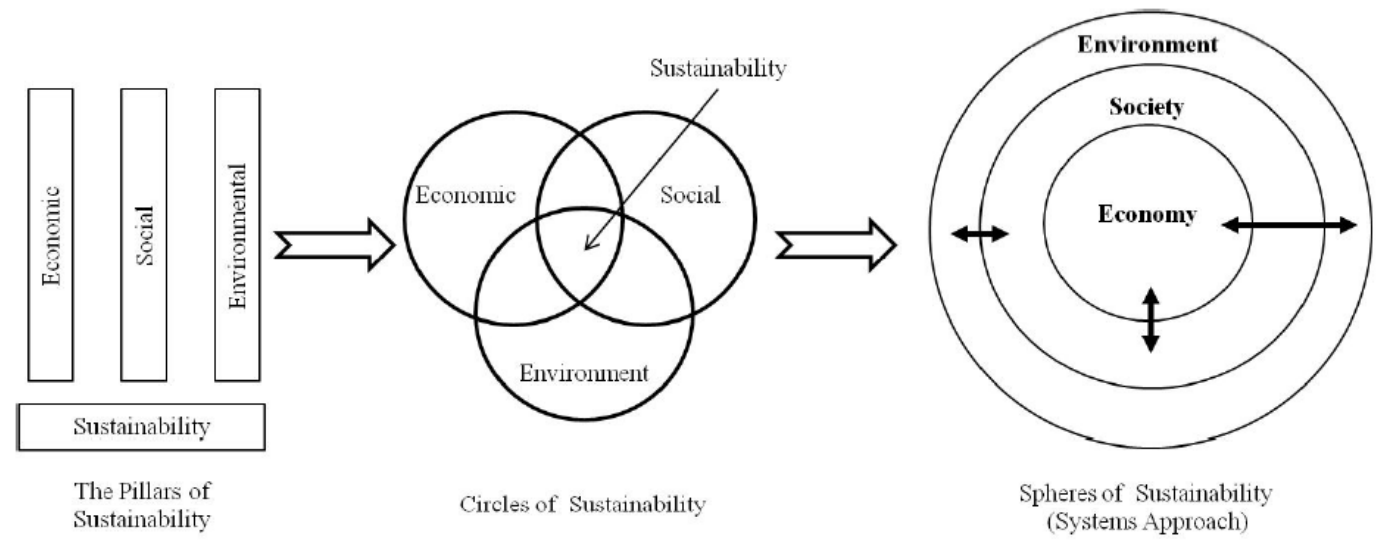

Figura 1 - Evolução do esquema de sustentabilidade.

Fonte: (Ostrom, 2009).

As relações e conexões entre as dimensões, em especial, a econômica e a ambiental, parecem estar em conflito e competição constante quando o tema é a sustentabilidade. A dimensão ambiental, capital natural, pode ser interpretada como fator limitante ao crescimento econômico, visto que apresenta recursos finitos para o abastecimento do sistema capitalista (Simons et al., 2001). Segundo Barbieri, Vasconcelos, e Andreassi (2010), o crescimento econômico como condição necessária para erradicar a pobreza, um objetivo do desenvolvimento sustentável constante no relatório da CMMAD (Comissão Mundial sobre Meio Ambiente e Desenvolvimento [CMMAD], 1991), encontra muitas objeções, pois há quem entenda que o crescimento econômico é a origem dos graves problemas ambientais e sociais observados no mundo contemporâneo. Para Boff (1995), a sustentabilidade deve superar a economia capitalista para evitar um futuro indesejável.

A respeito do conflito estabelecido entre as esferas do sistema e o comprometimento da qualidade ambiental e social, sobrepujados em função do crescimento econômico, há experiências relevantes e de sucesso que se baseiam em um modelo econômico capitalista, porém menos agressivos na política de lucros, com maior responsabilidade socioambiental, e, portanto, com caráter mais sustentável. O crescimento econômico é algo sempre desejado e perseguido por empresários e políticos, o que explicaria a grande adesão que eles deram ao movimento da sustentabilidade (Barbieri et al., 2010). 
A literatura em desenvolvimento sustentável e gestão da sustentabilidade indica que o primeiro passo para adoção de um sistema é a identificação de características e a disponibilidade de recursos ambientais (Nunes, Alamino, Shaw, \& Bernett, 2013). A sustentabilidade nos segmentos empresariais e do terceiro setor pode apresentar caráter de valor intrínseco às atividades executadas. Ou seja, pode ser uma prática adotada como diretriz para toda e qualquer atividade associada àquele setor. Em relação ao ambiente corporativo, podemos observar que a sustentabilidade internalizada nos negócios da empresa. Isso porque nos últimos anos, os negócios foram vistos como grande causa de problemas sociais, ambientais e econômicos. Empresas são amplamente percebidas por estarem prosperando às custas de toda comunidade $e$ quanto mais começaram a abraçar a responsabilidade corporativa, mais foram responsabilizadas por falhas na sociedade (Porter \& Kramer, 2011). De qualquer maneira, as organizações empresariais apresentam um papel especial na articulação do conceito e prática de sustentabilidade na sociedade.

Por todas as pressões sociais inerentes ao processo produtivo, entende-se que as empresas estão buscando formas de cativar seus clientes e consumidores adotando práticas sustentáveis, mudando o panorama ao longo dos anos. As organizações apresentam uma tendência de possuir estruturas, normas, modelos cognitivos e tecnologias similares. 0 chamado "Isomorfismo Estrutural" faz com que sejam incorporados os elementos legitimados exteriormente, muito mais do que pela eficiência que podem lhe proporcionar (Barbieri et al., 2010).

Sob essa ótica, os sistemas de mensuração do desenvolvimento sustentável (SMDS) tornam-se elementos institucionais fundamentais para empresas que atuam de forma competitiva nos diferentes mercados, isso porque esses elementos institucionais reduzem as incertezas e turbulências do ambiente, fato que promove o êxito e a sobrevivência da organização (Barbieri et al., 2010).

Apesar de fundamental, a busca por padrões de iniciativas de sustentabilidade ainda se mostra pouco expressiva e, portanto, se tornando relevantes para as organizações. Segundo Delai (2006), várias lacunas ainda limitam a operacionalização do desenvolvimento sustentável nas empresas. Uma delas é a questão da "Responsabilidade Social", uma vez que os problemas sociais são periféricos e não o negócio principal das organizações (Porter \& Kramer, 2011).

Outra lacuna está relacionada a falta de um conjunto de medidas-padrão de sustentabilidade amplamente aceitas (Searcy, Karapetrovic, \& Mccartney, 2005). Segundo Warhurst, 2002 e citado por Delai, 2006, a proliferação de indicadores e metodologias leva a necessidade de definir padrões metodológicos e conjuntos de indicadores comuns e desenvolver mecanismos apropriados para a incorporação de indicadores e metodologias existentes nos sistemas de mensuração.

Tenho em vista o cumprimento de diversos sistemas de mensuração de sustentabilidade por uma mesma empresa, devido aos fins que cada um deles está vinculado, esta prática se torna bastante onerosa em relação ao tempo e ao custo dos processos de certificação.

Diante do cenário apresentado, este artigo apresenta alguns pontos comuns e divergentes os principais Sistemas de Mensuração da Sustentabilidade, visando práticas de real valor agregado para organizações e sociedade. 


\section{REVISÃO BIBLIOGRÁFICA}

O que hoje chamamos de "Desenvolvimento Sustentável" tem evoluído como um conceito integrador, um guarda-chuva sob o qual um conjunto de questões inter-relacionadas pode ser organizado. Trata-se de um processo variável de mudança que busca como objetivo final a sustentabilidade em si (Sartori, Latrônico, \& Campos, 2014).

O primeiro passo de evolução se deu a partir do Clube de Roma - uma associação de cientistas políticos e empresários preocupados com estas questões globais. Como resultado, em 1972, surge um dos mais conhecidos estudos decorrentes da ação do Clube de Roma, o relatório mundialmente conhecido "The limits to growth" (Delai, 2006).

Segundo Guimarães (1998), as raízes do conceito de desenvolvimento sustentável encontram-se na Conferência de Estocolmo também de 1972, quando, pela primeira vez, chamou-se atenção para os impactos negativos do processo de desenvolvimento no meio ambiente e no tecido social, ocasião na qual tomadores de decisão do mundo inteiro foram alertados sobre a existência de outras dimensões do desenvolvimento, para além da dimensão econômica.

Atualmente, a definição mais usual e aceita de desenvolvimento sustentável, ou de sustentabilidade, tem sido a propugnada pelo Relatorio Brundtland, de 1987, difundida durante a realização da Rio-92, que considera atender às necessidades do presente sem comprometer a satisfação das necessidades das gerações futuras (World Commission on Environment and Development [WCED], 1987). Este conceito surge no momento em que se reconhece que o padrão de desenvolvimento em curso, que tem tido como objetivo central o progresso econômico, apresenta situações impossíveis do ponto de vista biofísico quando projetado para o futuro (Goodland, 1995). Apresenta ainda o paradoxo do incremento nos índices macroeconômicos, mas de deterioração de índices socioambientais (Boisier, 1997). Tanto os limites biofísicos do Planeta, como a deterioração do tecido social, ensejam mudanças nos processos de decisão, implementação e avaliação de políticas públicas, na busca de uma nova forma de desenvolvimento. Essas mudanças suscitam a necessidade de conscientizar a sociedade sobre a situação ambiental e social em que se encontra, de modo que possa participar da definição dos rumos do desenvolvimento que deseja.

Para Elkington (1994, 2001), criador do termo Triple Bottom Line, a sustentabilidade é o equilíbrio entre os três pilares: ambiental, econômico e social. A expectativa de que as empresas devam contribuir de forma progressiva com a sustentabilidade surge do reconhecimento de que os negócios precisam de mercados estáveis, e que devem possuir habilidades tecnológicas, financeiras e de gerenciamento necessário para possibilitar a transição rumo ao desenvolvimento sustentável.

Existem muitas outras definições diferentes da primeira exposta. E uma dela é de que diferencia o desenvolvimento sustentável como sendo um objetivo a ser alcançado e a sustentabilidade é o processo para atingir o Desenvolvimento Sustentável (Sartori et al., 2014). Todo esse processo de mudança pressupõe ainda pensar estrategicamente os impactos positivos e negativos de decisões e ações tomadas pela sociedade. Isso significa deixar de ter como meta somente o retorno econômico e incorporar outras dimensões à avaliação da realidade, considerando que o processo de desenvolvimento não é constante nem estável no tempo e no espaço. A partir dessa nova consciência, percebe-se que o desenvolvimento está sujeito tanto ao comportamento dos seres humanos, individual e coletivamente, e os processos sociais existentes em cada território; quanto ao tempo que os ambientes naturais levam para se recuperar e conservar a integridade dos ciclos vitais. Isso nos leva a pensar no compromisso e na 
responsabilidade das gerações presentes em relação às gerações futuras. Todavia, o conceito de desenvolvimento sustentável coloca em questão o entendimento que se tem dado à sustentabilidade, indicando que ambos estão longe de ser unânimes.

O termo sustentabilidade é utilizado, mas pouco explicado. Há uma inconsistente interpretação e aplicação, além de um alto grau de ambiguidade do conceito, incluindo uma percepção incompleta dos problemas de pobreza, da degradação ambiental e do papel do crescimento econômico (Lélé, 1991; Christodoulou, 2012; Slimane, 2012 como citado em Sartori et al., 2014).

Caracteriza-se a sustentabilidade como um princípio aplicável a sistemas. Sistemas abertos, para interagir com a sociedade-natureza, envolvendo sistemas industriais, sistemas sociais e sistemas naturais, incluindo os fluxos de informações, bens, materiais e resíduos. Isto é, a sustentabilidade envolve uma interação com sistemas dinâmicos que estão em constante mudança e necessitam de medidas proativas (Sartori et al., 2014).

Por fim, a operacionalização do conceito de desenvolvimento sustentável na construção de indicadores não ocorre de forma imparcial. Cada proposta privilegia determinados indicadores em detrimento de outros, sinalizando mudanças potenciais, sobre as quais cabem reflexões preliminares.

\subsection{A origem dos sistemas de mensuração do desenvolvimento sustentável}

A mensuração sistemática e rigorosa dos fenômenos sociais no mundo ocidental data da primeira metade do século XX, mais a partir dos anos 1970, com o surgimento da agenda ambiental e do conceito de desenvolvimento (Guimarães \& Feichas, 2009). A globalização também contribuiu para a intensificação da tendência a parametrizar todas as questões socioambientais. Entretanto, a complexidade dos fenômenos sociais e ambientais não é captada por simples parâmetros e relações de causalidade e a forma de medir sustentabilidade nas diferentes regiões e países é incerta. Isso reflete que o conceito seja menos útil quando utilizado para medir sustentabilidade de negócios, resultando em frequente falta de acurácia nas conclusões (Shrivastava \& Berger, 2010).

Para que esta condição seja incluída nos processos de mensuração de maneira efetiva e real, é preciso agregar uma interpretação que considere questões qualitativas, históricas e também institucionais. É importante ter em mente, portanto, que todo e qualquer tipo de mensuração apresenta limites e não espelha a complexidade da sociedade (Guimarães \& Feichas, 2009). As dificuldades estão na definição de medida unificada para performance em sustentabilidade (Shrivastava \& Berger, 2010).

Com a publicação do relatório Brundtland, a questão ambiental ganhou outra proporção, impulsionando pesquisas sobre indicadores de sustentabilidade. O Canadá e outros países da Europa foram os pioneiros em tentar delinear indicadores de sustentabilidade (Quiroga, 2001). 0 trabalho com este tema, no entanto, se intensificou depois da RIO-92, com iniciativas da Comissão de Desenvolvimento Sustentável e outras propostas nacionais que incentivaram o progresso na área. É importante ressaltar que a Agenda 21, iniciativa proposta na Declaração da Conferência do Rio de Janeiro, no seu capítulo 40, recomenda a implementação de indicadores de desenvolvimento sustentável.

Há várias definições sobre o que é um indicador. Um indicador pode ser quantitativo e qualitativo, não sendo restrito a apenas uma dessas esferas. Um indicador não é apenas uma estatística, ele representa uma variável que assume um valor em um tempo específico. Por sua 
vez, uma variável é uma representação de um atributo de um determinado sistema, incluindo qualidade, característica e propriedade (Ibidem). Em uma visão mais abrangente, o gerenciamento e a tomada de decisão de temas complexos nas organizações demandam métodos para representar temas por meio de unidades de medida simples; esses são os chamados indicadores - informações condensadas para tomada de decisão (Olsthoorn, Tyteca, Wehrmeyer, \& Wagner, 2000). Finalmente, o objetivo de um indicador é apontar a existência de riscos, potencialidades e tendências no desenvolvimento de um determinado território para que, em conjunto com a comunidade, decisões possam ser tomadas de forma mais racional (Unstall, 1994; Guimarães, 1998). Portanto, indicadores, no sentido que estamos trabalhando, são um conjunto de sinais que facilitam a avaliação do progresso de uma determinada empresa na busca pelo desenvolvimento sustentável, sendo ferramentas crucias no processo de identificação de problemas, reconhecimento dos mesmos, formulação de políticas, sua implementação e avaliação.

A escolha e uso de indicadores ambientais por empresas depende do tipo de empresa, seu setor, tamanho, proximidade de mercados consumidores sensíveis às questões ambientais, tipo e grau de regulamentações ambientais e cultura coorporativa da organização (Olsthoorn et al., 2000). Ainda segundo esses autores, o processo de desenvolvimento de indicadores apropriados apresenta os seguintes elementos-chave:

1 - Coleta de dados na empresa sobre indicadores físicos;

2 - Estabelecimento da base de dados com indicadores e seus fatores potenciais;

3 - Um local onde seja viável agregar diferentes indicadores por categoria num único indicador de impacto;

4 - Compilar esses dados em indicadores de desempenho usando padronização e normalizações.

Para Delai (2006), o conceito de Sistema de Mensuração do Desenvolvimento Sustentável pode ser definido como um conjunto de processos, pessoas, métodos, ferramentas e indicadores estruturados para coletar, descrever e representar dados com o objetivo de gerar informações sobre o desempenho em relação à sustentabilidade, auxiliando a tomada de decisão.

Em um contexto de institucionalização, esses sistemas não foram investigados sistematicamente (Bustami, Na, Bustami, A'Mmaari, \& Nasruddin, 2013). Em particular, pouca atenção foi dada às análises comparativas dos sistemas. Esses autores analisaram comparativamente a Norma ISO 26.000 e o Global Report Initiative (GRI), mostrando que tanto a ISO 26.000 quanto o GRI foram desenvolvidos devido à necessidade de institucionalização e padronização da Responsabilidade Social Corporativa. Todavia, segundo os autores, o GRI é dominado pela visão "pró-mercado" enquanto a ISO 26000 aparenta ser direcionado por uma visão "pró-sociedade civil”. Delai (2006) propôs um modelo de referência analisando oito SMDS, três dos quais são objeto desse trabalho (GRI, Dow Jones Sustainability Index e Indicadores Ethos). Já Strobel, Coral, e Selig (2004) propuseram uma análise comparativa para estabelecer as principais diferenças e similaridades entre o Dow Jones Sustainability Index, o GRI e os Indicadores Ethos. Os resultados demonstram que as iniciativas diferem principalmente em relação aos objetivos, abrangência e aplicabilidade, sendo o GRI a que mais converge com o conceito de sustentabilidade corporativa. No entanto, as três abordagens demonstraram lacunas no relacionamento das variáveis econômicas com as variáveis ambientais e sociais (Strobel et al., 2004). 


\section{METODOLOGIA}

Nesta seção serão apresentados a abrangência e os procedimentos metodológicos utilizados pela pesquisa contida neste artigo.

\subsection{Abrangência}

Apesar do contexto global ao qual o assunto sobre Sistemas de Mensuração do Desenvolvimento Sustentável vem sendo discutido, para garantir a efetividade metodológica, o foco deste estudo teve como objeto 5 desses sistemas. Tendo como referência Delai (2006), os critérios gerais utilizados na escolha foram: abordagem de pelo menos três dimensões do desenvolvimento sustentável, foco empresarial, estarem alinhados com as instâncias em que estão inseridos e não estarem baseados em outros sistemas, propondo somente algumas modificações.

Adicionalmente, por experiência profissional, no que tange o grau de importância dos Sistemas de Mensuração do Desenvolvimento Sustentável, foram escolhidos aqueles mais presentes no segmento empresarial. Baseado nos critérios acima elencados, os sistemas objeto deste trabalho foram: Global Reporting Initiative (GRI); Índice Dow Jones de Sustentabilidade (DJSI); Indicadores Ethos de Responsabilidade Social Empresarial; Índice de Sustentabilidade Empresarial Bovespa (ISE); e Norma ABNT NBR ISO 26.000:2010.

Dado a diversidade dos sistemas e o enfoque deste estudo comparativo, optou-se por determinar as correlações em grau mais detalhado apenas na dimensão ambiental, detalhada no capítulo de desenvolvimento do presente trabalho.

\subsection{Procedimentos Metodológicos}

A metodologia proposta neste estudo teve como objetivo seguir três estágios principais: (i) definição do método para desenvolvimento da avaliação por meio de revisão bibliográfica; (ii) análise comparativa entre os cinco sistemas de mensuração do Desenvolvimento Sustentável e (iii) definição de matriz comparativa entre os sistemas para a dimensão ambiental.

No primeiro estágio, definiu-se com base em pesquisa bibliográfica, um conjunto de categorias a serem utilizadas na análise comparativa das iniciativas. Com base em Delai (2006), utilizou-se o método da análise comparativa entre os sistemas tendo em vista a identificação da complementariedade dos mesmos e seu conteúdo de avaliação. Esse procedimento consiste em 3 grandes passos:

- Definição da estrutura do sistema;

- Definição do conteúdo de cada nível;

- Avaliação da esfera de abrangência e dos dados do sistema.

A identificação das características e etapas de desenvolvimento dos SMDS seguiu a partir de pesquisa bibliográfica em fontes secundárias, exclusivamente aos manuais e informações oficias desses sistemas, a fim de identificar seus conceitos, métodos e etapas de desenvolvimento.

Já no segundo estágio, realizou-se: definição do conceito de sustentabilidade dos diferentes sistemas, além da definição de seus conteúdos por meio de análises do processo de mensuração. Portanto, os SMDS foram comparados sob a ótica do conceito de Sustentabilidade, níveis de abstração e comparações na dimensão principal deste estudo (Ambiental), gerando a 
matriz de complementariedade (terceiro estágio) que permitiu conclusões sobre as interações e diferenças. A ilustração do conceito de níveis de abstração é apresentada na Figura 2.

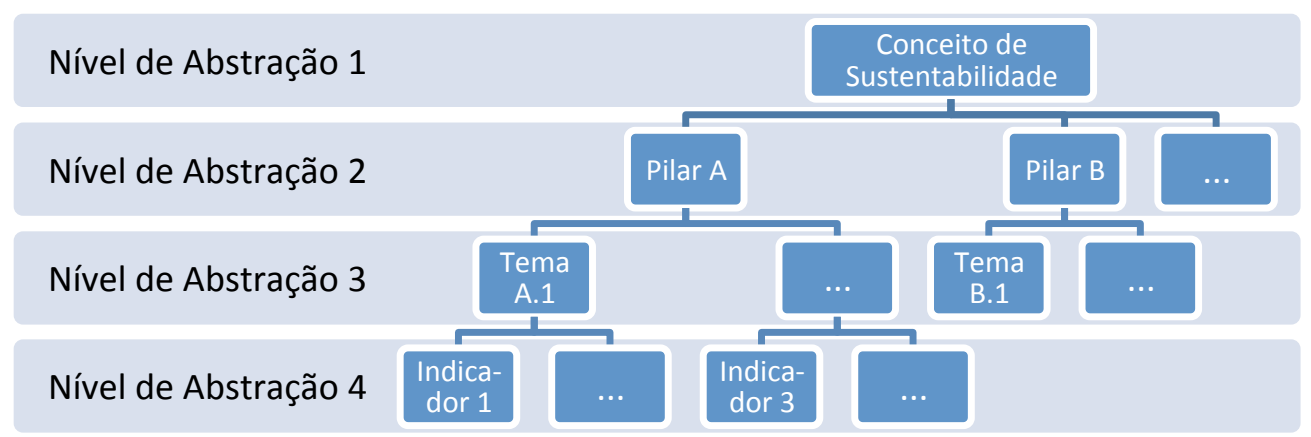

Figura 2 - Conceito de níveis de abstração dos SMDS

Fonte: Autor.

Assumindo como premissa que os sistemas devem ser baseados em um conjunto de categorias explícitas que relacionem a visão e as metas aos indicadores e aos critérios de avaliação (Delai, 2006), a análise proposta por este estudo pôde ser executada.

\section{DESENVOLVIMENTO E DISCUSSÃO}

\subsection{OS SISTEMAS DE MENSURAÇÃO DO DESENVOLVIMENTO SUSTENTÁVEL ESCOLHIDOS}

\subsubsection{Global Reporting Initiative (GRI)}

Lançado em 1997 pela Organização Não-Governamental americana Coalition for Environmentally Responsible Economics (CERES) e pela United Nations Environment Programme, o GRI trata-se, essencialmente, de um guia para elaboração de relatórios de sustentabilidade. Ele tem por objetivo auxiliar as empresas e suas partes interessadas no entendimento e comunicação das contribuições da organização ao alcance do desenvolvimento sustentável, melhorando a qualidade e utilidade dos relatórios de sustentabilidade (GRI, 2013). Algumas versões do Tripple Bottom Line usam unidades monetárias para medir performance econômica, social e ambiental, enquanto que outras versões, tais como o GRI, utilizam uma ampla gama de indicadores para medir a performance em sustentabilidade (Lamberton, 2005).

Atualmente, o GRI está em sua quarta geração, denominada G4. As Diretrizes G4 foram planejadas e desenvolvidas para oferecer orientações mais adequadas e atualizadas para a preparação eficaz de relatórios de sustentabilidade. Tem como objetivo ajudar os relatores a elaborar relatórios de sustentabilidade relevantes, que incluam informações valiosas sobre as questões de sustentabilidade mais cruciais para a organização, bem com tornar o processo de relato de sustentabilidade uma prática padrão (Global Reporting Initiative [GRI], 2014).

\subsection{2 Índice Dow Jones de Sustentabilidade (DJSI)}

O DJSI foi estabelecido em 1999 e avalia o desempenho das empresas líderes mundiais em sustentabilidade que operam no mercado de ações. A família de carteiras do DJSI é oferecida 
numa colaboração entre a bolsa de valores norte-america Dow Jones e a consultoria também norte-americana RobecoSAM (Dow Jones Sustainability Index [DJSI], 2013).

O DJSI acompanha o desempenho das ações das empresas em termos de critérios econômicos, ambientais e sociais e é composto por uma série de índices de diferentes carteiras, de acordo com critérios geográficos e por segmento de negócio.

Os índices apresentam representatividade global e servem como referência para os investidores que integram as considerações de sustentabilidade em seus investimentos, além de fornecerem uma plataforma de engajamento efetivo para as empresas que querem adotar as melhores práticas sustentáveis.

\subsubsection{Indicadores Ethos}

Os Indicadores Ethos compõem de um conjunto de indicadores lançado em 2002 pela organização não-governamental Instituto Ethos para servir de ferramenta de auto avaliação do desempenho organizacional em relação às práticas de responsabilidade social (Ethos, 2013). São uma ferramenta de gestão, de uso gratuito, que visa apoiar as empresas na incorporação da sustentabilidade e da responsabilidade social empresarial (RSE) em suas estratégias de negócio, de modo que este venha a ser sustentável e responsável (Ethos, 2014). Embora traga medidas de desempenho em sustentabilidade e responsabilidade social, esta ferramenta não se propõe a medir o desempenho das empresas, nem a reconhecê-las como sustentáveis ou responsáveis.

O conteúdo atual dos Indicadores Ethos preserva a estrutura que o consolidou como ferramenta de aprendizado: questões de profundidade (estágios), questões binárias e questões quantitativas.

\subsection{4 Índice de Sustentabilidade Empresarial (ISE - BM\&F-BOVESPA)}

O Índice de Sustentabilidade Empresarial (ISE) busca criar um ambiente de investimento compatível com as demandas de desenvolvimento sustentável da sociedade contemporânea e estimular a responsabilidade ética das corporações. Iniciado em 2005, foi originalmente financiado pela International Finance Corporation (IFC), braço financeiro do Banco Mundial, e seu desenho metodológico é de responsabilidade do Centro de Estudos em Sustentabilidade (GVCes) da Escola de Administração de Empresas de São Paulo da Fundação Getúlio Vargas (FGV-EAESP). O ISE é uma ferramenta para análise comparativa da performance das empresas listadas na BM\&FBOVESPA sob o aspecto da sustentabilidade corporativa, baseada em eficiência econômica, equilíbrio ambiental, justiça social e governança corporativa (Bolsa de Mercadorias \& Futuros Bolsa de Valores de São Paulo [BM\&F-BOVESPA], 2013). A missão do ISE é induzir as empresas a adotarem as melhores práticas de sustentabilidade empresarial e apoiar os investidores na tomada de decisão de investimentos socialmente responsáveis (BM\&F-BOVESPA, 2014).

O ISE também amplia o entendimento sobre empresas e grupos comprometidos com a sustentabilidade, diferenciando-os em termos de qualidade, nível de compromisso com o desenvolvimento sustentável, equidade, transparência e prestação de contas, natureza do produto, além do desempenho empresarial nas dimensões econômico-financeira, social, ambiental e de mudanças climáticas (BM\&F-BOVESPA, 2014). 
O ISE trabalha sob a ótica de alguns pressupostos e objetivos estratégicos, listados abaixo (BM\&F-BOVESPA, 2014):

Buscar constante alinhamento com os temas e desafios globais da sustentabilidade;

Promover a melhoria contínua das estratégias e práticas empresariais em sustentabilidade.

\subsubsection{ABNT NBR ISO 26.000: 2010 - Diretrizes sobre Responsabilidade Social}

A International Organization for Standardization (ISO) foi criada oficialmente em 1947, por uma iniciativa de 25 países, com o objetivo de facilitar a coordenação e unificação, no âmbito internacional, de normas industriais. Sediada em Genebra, a ISO se constitui, atualmente, na maior organização do mundo de desenvolvimento de normas técnicas internacionais. É uma organização não governamental, integrada pelos principais organismos nacionais de normalização, tendo um representante por país, contando, atualmente, com 153 membros. A Organização Mundial do Comércio (OMC) possui uma parceria estratégica com a ISO, no sentido de promover um sistema mundial de comércio em bases igualitárias. Os signatários do Acordo sobre Barreiras Técnicas ao Comércio (TBT) se comprometeram a promover e utilizar normas internacionais do tipo das desenvolvidas pela ISO, que proporcionam uma linguagem técnica comum entre fornecedores e clientes. As normas das famílias ISO 9000 (sistemas de gestão da qualidade) e ISO 14000 (sistemas de gestão ambiental) estão entre as mais amplamente conhecidas e bem sucedidas normas já elaboradas. As normas ISO 9000 se tornaram uma referência internacional para os requisitos de qualidade e as normas ISO 14000 ajudam as organizações a vencerem seus desafios ambientais (Melo, 2006).

A norma ABNT ISO 26000, publicada pela Associação Brasileira de Normas Técnicas foi publicada em 2010 e estabelece que a responsabilidade social se expressa pelo desejo e pelo propósito das organizações em incorporarem considerações socioambientais em seus processos decisórios e a responsabilizar-se pelos impactos de suas decisões e atividades na sociedade e no meio ambiente. Isso implica num comportamento ético e transparente que contribua para o desenvolvimento sustentável, que esteja em conformidade com as leis aplicáveis e seja consistente com as normas internacionais de comportamento. Também implica que a responsabilidade social esteja integrada em toda a organização, seja praticada em suas relações e leve em conta os interesses das partes interessadas. Lançada em 2010, é uma norma de diretrizes e de uso voluntário; não visa e nem é apropriada para fins de certificação (Associação Brasileira de Normas Técnicas [ABNT], 2013).

Uma de suas características centrais é a presença do princípio de Engajamento das partes interessadas, demonstrando um esforço em garantir à norma a manutenção da gestão socialmente responsável, fator de extrema importância, uma vez que a norma se constitui numa potencial referência mundial (Melo \& Gomes, 2006). Esse engajamento abre o diálogo com públicos nunca ou pouco explorados antes pelas organizações, tendendo a gerar maior benefício difuso de cada atividade. 


\subsection{ANÁLISE COMPARATIVA E RESULTADOS}

Como base para qualquer Sistema de Mensuração do Desenvolvimento Sustentável (SMDS), o conceito de Sustentabilidade é apresentado em todos os sistemas objeto deste estudo conforme avaliação qualitativa dos conteúdos oficiais publicados. Nesse sentido, é apresentado no quadro abaixo a síntese do conceito foco, de maneira individualizada para cada um dos SMDS.

SMDS

Foco do Conceito de Sustentabilidade

GRI

Equilíbrio nas complexas relações atuais entre necessidades econômicas, ambientais e sociais que não comprometa o desenvolvimento futuro (resultado triplo).

DJI

Uma abordagem de negócios que cria valor de longo prazo aos acionistas por meio do aproveitamento das oportunidades e do gerenciamento dos riscos derivados dos desenvolvimentos econômico, social e ambiental.

ETO

A Responsabilidade Social Empresarial é encontrar uma forma de gerenciar os negócios atendendo às exigências de competitividade, contemplando aspectos do desenvolvimento sustentável e atendendo a reivindicações da sociedade civil e não está restrita as ações da empresa com a comunidade, implicando também no diálogo e gestão que resultem na qualidade do seu relacionamento com os demais públicos envolvidos: empregados, consumidores, clientes, fornecedores, meio ambiente, governo e sociedade.

ISE

Eficiência econômica, equilíbrio ambiental, justiça social e governança corporativa, visa ampliar o entendimento sobre empresas e grupos comprometidos numa perspectiva de longo prazo.

ISO

Desenvolvimento que integra as necessidades do presente sem comprometer a habilidade de futuras gerações a também integrar suas próprias necessidades. Refere-se a integração de objetivos de alta qualidade de vida, saúde, e prosperidade com justiça social e manutenção da capacidade suporte da Terra em todas suas diversidades.

Quadro 1 - Conceito de Sustentabilidade nos SMDS estudados

Fonte: Ethos, 2013; DJSI, 2013; Ethos, 2013, BM\&F-BOVESPA, 2013; ABNT, 2013; GRI, 2014.

GRI = Global Reporting Initiative.

DJI = Índice Dow Jones de Sustentabilidade

$\mathrm{ETO}=$ Indicadores Ethos.

ISE = Índice de Sustentabilidade BM\&F-Bovespa

ISO = Norma ABNT NBR ISO 26.000:2010 
Com a análise das definições de sustentabilidade para cada um dos SMDS, verificou-se a convergência entre os sistemas no uso do conceito de resultado triplo - equilíbrio dos impactos econômico, social e ambiental que não comprometa o desenvolvimento futuro - do Relatório Brundtland (World Commission on Environment and Development [WCED], 1987). Tendo essa percepção, sugere-se que apesar das formas distintas, os sistemas tendem a apresentar pontos em comum e complementares, pois em última análise partilham do objetivo de propiciar melhora na gestão para organizações com o foco na sustentabilidade, sendo este um conceito muito próximo como observado na tabela acima. Contudo, a forma de cada SMDS é distinta e para uma análise de complementariedade seria necessário identificar os diferentes níveis de desdobramento do conceito de sustentabilidade, até seu menor nível dentro do sistema.

Para tal, cada um dos sistemas foi criteriosamente analisado para se obter a forma de desdobramento, chamados de fatores operacionais. Portanto, fatores operacionais são os níveis de desdobramento dos Sistemas de Mensuração do Desenvolvimento Sustentável, partindo de seu conceito mais abrangente até seu menor grau de interação. O Quadro 2 apresenta os resultados avaliados. Importante ressaltar que apesar de alguns nomes distintos, buscou-se compilar conteúdos similares para cada um dos níveis, dando visibilidade a estruturação de hierarquização de cada um dos sistemas.

\begin{tabular}{cccccccc}
\hline SMDS & Nível 1 & Nível 2 & Nível 3 & Nível 4 & Nível 5 & Nível 6 & Nível 7 \\
\hline GRI & - & - & Dimensão & Categoria & Aspecto & - & Indicadores \\
DJI & - & Índice & Dimensão & Critério & - & Perguntas \\
ETO & - & - & Dimensão & Temas & Subtemas & Questões \\
ISE & Princípios & Índice & Dimensão & Critério & Grupo de & Perguntas \\
\hline ISO & Princípios & - & Práticas & Indicadores & - \\
\hline
\end{tabular}

\section{Quadro 13 - Níveis de Fatores Operacionais dos SMDS estudados}

Fonte: Ethos, 2013; DJSI, 2013; Ethos, 2013, BM\&F-BOVESPA, 2013; ABNT, 2013; GRI, 2014.

Onde:

$\mathrm{GRI}=$ Global Reporting Initiative.

DJI = Índice Dow Jones de Sustentabilidade

$\mathrm{ETO}=$ Indicadores Ethos.

ISE = Índice de Sustentabilidade BM\&F-Bovespa

ISO = Norma ABNT NBR ISO 26.000:2010 
A análise permite verificar que o sistema GRI apresenta nível mais avançado no desdobramento de suas metas, até o detalhamento dos indicadores propostos. Já os demais SMDS estudados apresentam nível menos avançado no cascateamento das metas, todavia ainda com diferença entre eles. O menor nível observado nesses sistemas remete às "perguntas" ou "práticas" como no caso da ISO 26000, que refletem às ações declaradas da organização. Apesar do mesmo nível, percebeu-se nessa análise que os sistemas Índice Dow Jones de Sustentabilidade e ISE não sinalizam em seu conteúdo o desdobramento da visão de Sustentabilidade em metas concretas para as empresas, diferentemente dos sistemas Ethos e ISO 26.000, que voluntariamente sugerem maior integração de ações na rotina organizacional.

Após a distinção dos Fatores Operacionais dos SMDS, a análise de complementariedade foi realizada para a Dimensão Ambiental, com análise minuciosa de cada manual e seus documentos oficiais.

Foram encontrados e categorizados 41 subtemas divididos em 9 temas. Os Subtemas presentes nos cinco SMDS foram: Energia Consumida dentro da Organização; e Total de Água extraída.

Os subtemas presentes em quatro SMDS foram: Resíduos gerados e sua disposição; Percentual de materiais recicláveis utilizados; Redução de energia consumida; Descrição de impactos em áreas de alto valor em Biodiversidade; Habitats protegidos ou restaurados; Total de resíduos dispostos por tipo e forma de disposição; Emissões GEE Escopo 1; e Emissões GEE Escopo 2.

Os temas acima apresentados representam $24,39 \%$ do total, ou seja, quase $3 / 4$ ou $75 \%$ dos subtemas ainda apresentam considerável variação entre os SMDS. Claramente, os temas mais comuns aos SMDS representam os temas mais latentes na Dimensão Ambiental sob a ótica do interesse difuso com impacto causado pelas organizações.

Historicamente, a gestão do consumo de água e energia está diretamente relacionada com o passado de eficiência ambiental nas organizações, portanto temas mais consolidados e que receberam maior atenção dos gestores e da sociedade em geral. A hipótese de que estes temas deveriam ter maior atenção e consequente investimento das organizações poderia ser testada.

Sob a luz de comparação entre os SMDS, a tendência observada na definição dos Níveis de Fatores Operacionais pôde ser confirmada com a matriz de complementariedade. De forma muito despontada, o Sistema GRI se posiciona como o mais completo, não apenas em número de subtemas que envolve, mas também pelo critério quantitativo desta avaliação. Muito provavelmente deve-se ao fato de ter um viés de comunicação externa e transparência das organizações com suas partes interessadas. Num segundo patamar, podemos classificar os Sistemas Indicadores Ethos e ISO 26000, que de forma mais qualitativa compreendem cerca de $50 \%$ do campo amostral de subtemas. Nitidamente ambos os sistemas apresentam viés de gestão interna e otimização dos processos de gestão. Num terceiro patamar podemos classificar os Sistemas ISE e Dow Jones Index; justamente os sistemas vinculados aos mercados financeiros. Surgindo, portanto, uma nova hipótese para análise de trabalhos futuros. 


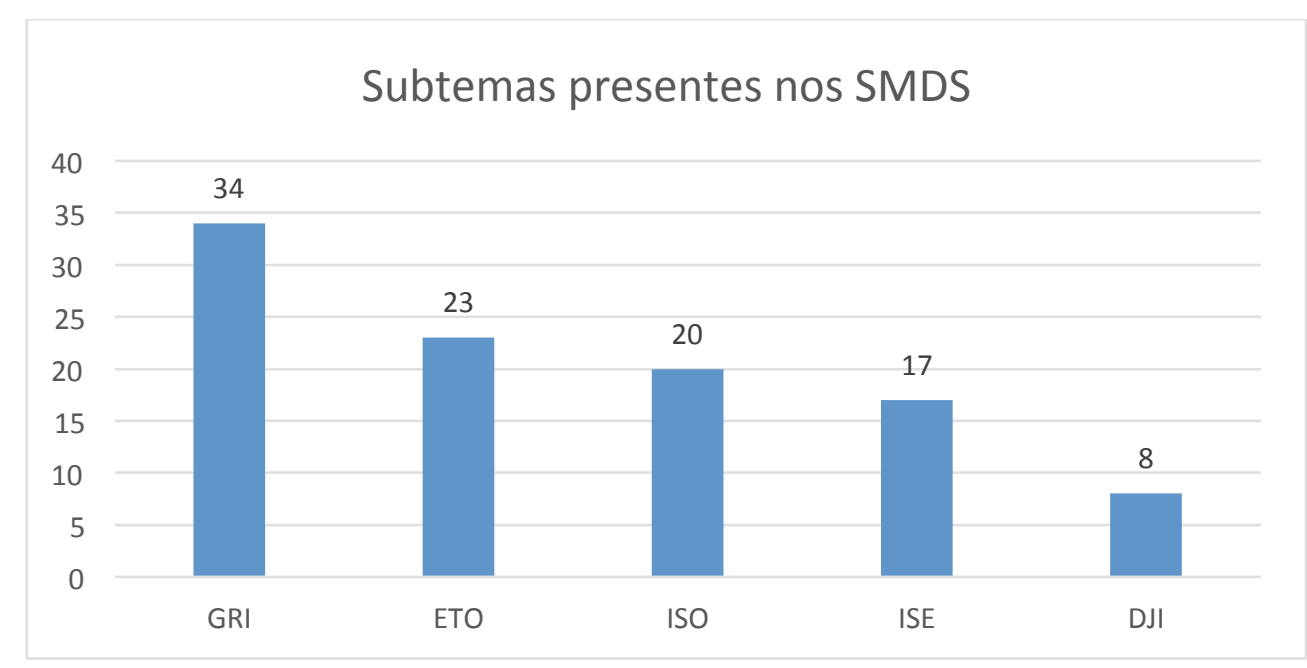

Gráfico 1 - Distribuição de Subtemas por SMDS

Fonte: Ethos, 2013; DJSI, 2013; Ethos, 2013, BM\&F-BOVESPA, 2013; ABNT, 2013; GRI, 2014.

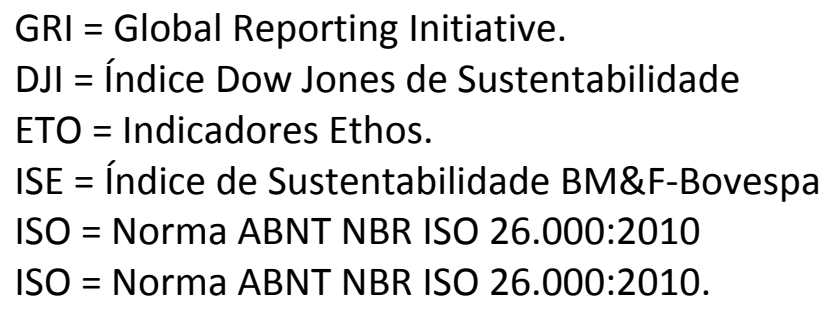

Pode-se inferir que os diferentes objetivos dos sistemas geram diferentes formas de abordagem e consequentemente diferentes resultados na gestão organizativa no campo da Sustentabilidade Empresarial. Quanto maior a aderência à real transparência e às diferentes partes interessadas, maior é o grau de profundidade do SMDS em seus fatores operacionais.

Portanto, para a correta utilização de qualquer um dos sistemas sistema, a organização deve ter claro qual o objetivo fim e os resultados esperados na escolha, tanto do ponto de vista da gestão interna, quanto do atendimento, às expectativas dos principais stakeholders.

\section{CONCLUSÕES}

A partir de toda avaliação proposta, este estudo consegue mostrar que a primeira característica fundamental de um sistema de mensuração da sustentabilidade corporativa é a existência de um conceito ou visão de sustentabilidade norteador, sendo este o alicerce para a delimitação do seu conteúdo, e seu desdobramento em metas. A avaliação comparativa entre os diferentes sistemas estudados demonstra também importante convergência no uso do conceito do resultado triplo - equilíbrio dos impactos econômico, social e ambiental que não comprometa o desenvolvimento futuro - do Relatório Brundtland. Esta constatação é um primeiro passo importante para transformar a sustentabilidade em algo concreto nas organizações, uma vez que o engajamento e a educação sobre o tema é peça fundamental, e a universalização desse 
conceito pode ser considerado como a primeira conquista para estágios futuros de comprometimento sob a ótica individual e coletiva.

Apesar de convergência no conceito de Sustentabilidade, no que tange o desdobramento dessa visão em ações concretas, este estudo permitiu classificar cada um dos sistemas com seus pontos convergentes e divergentes. Foram identificados sete níveis de fatores operacionais e diferente abordagem na análise dos SMDS. Podemos concluir que o GRI apresenta critérios mais profundos e detalhados na dimensão ambiental, sendo o único a objetivamente avaliar metas quantitativas na performance ambiental.

A análise de complementariedade também demonstra que a Dimensão Ambiental apresenta temas prioritários na abordagem empresarial, em especial: Água, Energia, Resíduos, GEE e Biodiversidade.

Apesar de suas limitações, este estudo pode ser entendido como um ponto de partida para criar profundidade nas complementariedades desses e de outros SMDS, permitindo desenvolvimento de novos sistemas ou adaptação dos existentes dentro das organizações. Espera-se fomentar melhores resultados a partir da tomada de decisão, uma vez que a implementação dos SMDS é onerosa e a correta utilização dessas ferramentas poderia privilegiar recursos para de fato ampliar a sustentabilidade da organização.

Tendo por base os resultados expostos, podemos concluir que o objetivo geral deste trabalho (desenvolver uma análise comparativa de cinco diferentes Sistemas de Mensuração do Desenvolvimento Sustentável, demonstrando as interações no conceito de sustentabilidade e níveis de estruturação em cada um deles) foi atendido.

\section{REFERÊNCIAS}

Associação Brasileira de Normas Técnicas. (2013). NBR ISO 26000:2010: Diretrizes sobre responsabilidade social. Rio de Janeiro: ABNT. Recuperado de http://www.inmetro.gov.br/qualidade/responsabilidade_social/iso26000.asp.

Barbieri, J. C., Vasconcelos, I. F. G., \& Andreassi, T. (2010). Inovação e sustentabilidade: novos modelos e proposições. Revista de Administração de Empresas, 50 (2).

Bolsa de Mercadorias \& Futuros - Bolsa de Valores de São Paulo. (2013). Índice de sustentabilidade empresarial. Recuperado de http://www.bmfbovespa.com.br/indices/Resumolndice.aspx?Indice=ISE\&idioma=pt-br.

Bolsa de Mercadorias \& Futuros - Bolsa de Valores de São Paulo. (2013). Índice de sustentabilidade empresarial: objetivos. Recuperado de http://isebvmf.com.br/?r=site/conteudo\&id=1\#objetivos.

Bolsa de Mercadorias \& Futuros - Bolsa de Valores de São Paulo. (2013). Metodologia do índice de sustentabilidade empresarial (ISE). Recuperado de http://www.bmfbovespa.com.br/Indices/download/ISE-Metodologia-pt-br.pdf.

Boff, L. (1995). Ecologia: grito da Terra, grito dos pobres. São Paulo: Ática. 
Boisier, S. (1997). El Vuelo de una cometa. Una metáfora para una teoría de desarrollo territorial. Revista Eure, 69.

Bustami, R., Na, D., Bustami, R., A’Mmaari, S. R., Nasruddin, E. (2013). Exploring ISO 26000 and Global Reporting Initiatives (GRI): a neo-institutional analysis of two CSR institutions. International Economics Letters, 2, 10-17.

Comissão Mundial Sobre Meio Ambiente e Desenvolvimento (CMMAD). (1991). Nosso futuro comum. Rio de Janeiro: Fundação Getúlio Vargas.

Delai, I. (2006). Uma proposta de modelo de referência para mensuração da sustentabilidade corporativa (Dissertação de Mestrado).Faculdade de Economia, Administração e Contabilidade de Ribeirão Preto, Universidade de São Paulo, Ribeirão Preto, SP, Brasil.

Dow Jones Sustainability Index. (2013). Dow Jones sustainability world indexes guide v.7.0. Recuperado de http://www.sustainability - indeces.com.

Dow Jones Sustainability Index. (2013). Dow Jones sustainability world indexes. Recuperado de http://djindexes.com/mdsidx/downloads/fact_info/Dow_Jones_Sustainability_World_Ind ex_Fact_Sheet.pdf.

Elkington, J. (1994). Towards the sustainable corporation: Win-win-win business strategies for sustainable development. California Management Review, 36(2).

Elkington, J. (2001). Canibais com garfo e faca. São Paulo: Makron Books.

Ethos. (2013). Indicators of corporate social responsibility. Recuperado de http://www.ethos.org.br.

Ethos. (2014). Indicadores Ethos para negócios sustentáveis e responsáveis. Recuperado de http://www3.ethos.org.br/conteudo/iniciativas/indicadores.

Global Reporting Iniative (GRI). (2014). Sustainability reporting guidelines. Recuperado de http://www.globalreportinginitiative.org.

Global Reporting Iniative (GRI). (2014). G4: Diretrizes para relato de sustentabilidade Princípios para relato e conteúdos padrão. Recuperado de http://www.globalreportinginitiative.org.

Goodland, R. (1995). The concept of environmental sustainability. Annual Review of Ecology and Systematics, 26(1), 1-24.

Guimarães, R. P. (1998). Aterrizando una Cometa: indicadores territoriales de sustentabilidad. Santiago do Chile: CEPAL/ILPES.

Guimarães, R. P. Feichas, S. A. Q. (2009). Desafios na construção de indicadores de sustentabilidade. Ambiente \& Sociedade, 12(2).

Lamberton, G. (2005). Sustainability accounting - a brief history and conceptual framework. Accounting Forum, 29(1). 
Melo, C. M. (2006). ISO 26000: Uma análise da elaboração da norma internacional de responsabilidade social (Dissertação de Mestrado). Universidade Federal Fluminense, Rio de Janeiro, RJ, Brasil.

Melo, C. M., Gomes, E. R. (2006). ISO 26000: Uma análise da norma internacional de responsabilidade social. Anais do Simpósio de Excelência em Gestão e Tecnologia-SEGeT. Resende, RJ, Brasil, 3.

Nunes, B., Alamino, R., Shaw, D., Bernett, D. (2013). Managing sustainability performance through the system fitness concept. Working Paper.

Olsthoorn, X., Tyteca, D., Wehrmeyer, W., Wagner, M. (2001). Environmental indicators for business: a review of the literature and standardization methods. Journal of Cleaner Production, 9(5), 2000.

Ostrom, E. (2009). A general framework for analysing sustainability of social-ecological systems science. Science, 325(419).

Porter, M. E., Kramer, M. R. (2011). Creating shared value. Harvard Business Review.

Quiroga, R. (2001). Indicadores de sustentabilidad y desarrollo sostenible: estado Del arte y perspectivas. Santiago de Chile: División de Medio Ambiente y Asentamientos Humanos.

Sartori, S., Latrônico, F., Campos, L. M. S. (2014). Sustentabilidade e desenvolvimento sustentável: uma taxonomia no campo da literatura. Ambiente \& Sociedade. 17(1).

Searcy, C., Karapetrovic, S., Mccartney, D. (2005). Designing sustainable development indicators: analysis for a case study. Measuring Business Excellence, 9(2).

Shrivastava, P., Berger, S. (2010). Sustainability principles: a review and directions. Organization Management Journal, 7(4).

Simons, L., Slob, A, Holswilder, H., Tukker, A. (2001). The fourth generation: new strategies call for new eco-indicators. Environmental Quality Management, (11), 51-61.

Strobel, J. S., Coral, E., Selig, P. M. (2004). Indicadores de sustentabilidade corporativa: uma análise comparativa. Anais do Encontro Anual da ANPAD. Curitiba, PR, Brasil, 28.

Unstall, D. (1994). Developing and using indicators of sustainable development in Africa: an overview, doc mimeo. The Network for Environment and Sustainable Development in Africa (NESDA), Thematic Workshop on Indicators of Sustainable Development. Banjul, Gambia: NESDA.

World Commission on Environment and Development - WECD. (1987). Our Common Future. Oxford: Oxford University Press. 